\title{
O PRINCÍPIO DA DIGNIDADE DA PESSOA HUMANA E A BANALIDADE DO MAL: BREVE ANÁLISE DOS DOCUMENTÁRIOS HOLOCAUSTO BRASILEIRO E FANTASMAS DE RUANDA
}

\author{
Benedito Sena dos Santos ${ }^{1}$
}

\begin{abstract}
RESUMO:
Este trabalho científico é o resulto final de uma avaliação da disciplina de Antropologia ministrada pela Professora Doutora Lauriani Porto Albertini, no curso de Licenciatura em Pedagogia do Instituto Superior Anísio Teixeira no ano de 2020. Tem como objetivo mostrar que o Estado possui responsabilidade pelas atrocidades acontecidas no Hospital Colônia de Barbacena e que ele feriu uma premissa constitucional, que é o Princípio da Dignidade Humana, e como a luta antimanicomial brasileira influenciou no fim das desumanidades ocorridas nos hospitais psiquiátricos. Para tanto, será usado como base teórica o conceito da banalidade do mal retratado nos documentários Holocausto Brasileiro, dirigido por Daniele Arbex de 2016, e Fantasmas de Ruanda, de 2004. Por fim, serão feitas comparações dos casos do Hospital Colônia de Barbacena e das crueldades ocorridas em Ruanda com os conceitos de etnocentrismo, racismo, poder e cultura, e será ainda discutido como o poder do Estado nesses casos provocou as tragédias sociais descritas pelos documentários. Além disso, busca-se apontar os prováveis responsáveis legais em ambos os acontecimentos, de acordo com os fatos históricos documentados.
\end{abstract}

PALAVRAS-CHAVE: Hospital Colônia de Barbacena. banalidade do mal. Ruanda e luta antimanicomial.

\begin{abstract}
:
This scientific work is the final result of an evaluation of the course of Anthropology taught by professor doctor Lauriani Porto Albertini, in the undergraduate course of Pedagogy at the Instituto Superior Anísio Teixeira in 2020. It aims to show that the State has responsibility for the atrocities that happened at Hospital Colônia de Barbacena and that it violated a constitutional premise, which is the Principle of Human Dignity, and how the Brazilian anti-asylum struggle influenced the end of the inhumanities that occurred in psychiatric hospitals. Therefore, the concept of the banality of evil portrayed in the documentaries Holocausto Brasileiro, directed by Daniele Arbex in 2016, and Fantasmas de Ruanda, in 2004, will be used as a theoretical basis. Finally, comparisons will be made between the cases of the Hospital Colônia de Barbacena and the cruelties that occurred in Rwanda and the concepts of ethnocentrism, racism, power and culture; there will also be a discussion about how the power of the State in these cases provoked the social tragedies described by the documentaries. In addition, it seeks to point out the probable legal individuals responsible for both events, according to the documented historical facts.
\end{abstract}

KEY WORDS: Hospital Colônia de Barbacena. banality of evil. Rwanda and anti-asylum struggle.

\section{Introdução}

Esse Artigo Científico é o resultado final de duas avaliações da disciplina de Antropologia do ISAT - Instituto Superior Anísio Teixeira em São Gonçalo. Esta disciplina foi ministrada pela Professora Doutora Lauriani Porto Albertini no primeiro semestre de 2020 para o curso de Pedagogia. A Professora nos apresentou os conceitos antropológicos de

\footnotetext{
${ }^{1}$ Graduando do 70 período do Curso de Licenciatura em Pedagogia pelo Instituto Superior Anísio Teixeira (ISAT) - São Gonçalo/RJ. Professor da Educação Básica e Pesquisador de Educação em Espaços de Privação de Liberdade.
} 
Universalismo e Relativismo dos Direitos Humanos, bem como de Genocídio e Etnocídio trabalhando, a partir de uma metodologia histórico-comparada, alguns genocídios e pediu para que víssemos inicialmente o documentário Fantasmas de Ruanda para debatermos. De igual maneira, também foi discutido e analisado os acontecimentos no Hospital Colônia de Barbacena a partir de fotos e relatos do livro de Daniela Arbex Holocausto Brasileiro, e do documentário homônimo.

Após a Professora trabalhar os conteúdos anteriores nos passou uma avaliação em que deveríamos primeiro ver os filmes documentários Fantasmas de Ruanda e Holocausto Brasileiro e após isso fazer uma correlação e dissertação dos acontecimentos de ambos os lugares com o conceito filosófico da Banalidade do mal de Hannah Arendt (1999). Como segunda avaliação da disciplina deveríamos uma relação do Holocausto Brasileiro com o Princípio da Dignidade Humana e a Responsabilidade Civil do Estado nos casos que ocorreram no Hospital Psiquiátrico e, além disso, deveríamos também responder por que o Estado não se responsabilizava pelas atrocidades em Barbacena. Pode-se afirmar que os trabalhos da disciplina serviram de inspiração para fazer este artigo científico, objetivando demonstrar a importância acadêmica dos assuntos dispostos.

Inicialmente será apresentado o documentário Holocausto Brasileiro e as ocorrências do Hospital Colônia de Barbacena, após isso relatarei os ocorridos e será descrito como a Luta antimanicomial influenciou no fim do Hospital Colônia. No terceiro momento do Artigo será feita uma descrição sobre o documentário Fantasmas de Ruanda e o Genocídio que aconteceu ali. Num quarto momento será feita uma comparação e análise do Princípio da Dignidade da Pessoa Humana e a Responsabilidade Civil do Estado no Hospital Colônia. E por fim, será uso do conceito de Banalização do Mal de Hannah Arendt para analisar os acontecimentos de Ruanda e de Barbacena.

\section{Documentário Holocausto Brasileiro}

O documentário Holocausto Brasileiro (2016) é baseado em um livro homônimo da autora e jornalista Daniela Arbex, onde ela relata acontecimentos de oito décadas de atrocidades no Hospital Colônia de Barbacena Minas Gerais. Essa obra cinematográfica tem como objetivo fazer com que as pessoas que viveram, trabalharam e testemunharam no Colônia pudessem expressar os seus sentimentos, ideias e vivencias, para que assim não fosse mais omitido o que ali aconteceu durante todo aquele tempo. 
O Hospital Colônia de Barbacena, foi o maior hospital psiquiátrico do Brasil, foi fundado em 1903 (o hospital fazia parte de um conjunto de sete hospitais psiquiátricos feitos na mesma região de Barbacena com a ideia de que como a cidade possui um clima ameno ali seria o melhor lugar para tratamento psiquiátrico) e inicialmente não aconteciam atrocidades, mas no período de 1930 a 1980 foi quando houve registros do maior genocídio do Brasil, onde 60 mil pessoas perderam suas vidas.

Já no início do filme nos é apresentada a chegada dos pacientes ao Colônia, como vinham de muitas outras cidades, os mesmos acabavam desembarcando de trem duas vezes por semana (Terças e Quintas), em um vagão reservado para os "loucos", a partir desse momento começaram a chamar esse meio de transporte de "trem de doidos". Compara-se essa chegada nos trens com as dos judeus nos campos de concentrações nazistas, já que esse era abastecido por trens. Também chegavam pacientes de outras cidades de Minas e esses muitas vezes também vinham de ônibus.

Após a chegada os pacientes inicialmente tomavam um banho de desinfecção e tinham suas cabeças raspadas, logo em seguida alguns recebiam roubas outros ficavam nus, se separava os pacientes por gênero e idade em locais distintos da instituição. Deve se levar em consideração que, de acordo com a pesquisa realizada por Arbex (2013), não havia um critério médico no momento da internação desses pacientes, por isso $70 \%$ das pessoas que ali eram internadas não tinham doença mental, eram pessoas saudáveis com algum tipo de desafetos com pessoas de fora (moças grávidas antes do casamento, esposas descartadas por seus maridos tidas como "histéricas", crianças "imperfeitas"), prostitutas, mendigos, homossexuais, presos políticos (considerando que o período de maior crescimento de internos foi durante a Ditadura), ou até mesmo pessoas abordadas na rua sem documentos - tais internações eram tidas como uma "higienização social", uma vez que eram depositados ali todos indesejáveis sociais.

Assim, a pesquisa demonstra que o Colônia perdeu o seu real motivo de ser um hospital e deixou de cuidar dos pacientes virou um lugar de amontoado de pessoas que a sociedade não queria mais proximidade. Não havia um cuidado específico para os transtornos mentais, os remédios eram ministrados conforme os cuidadores queriam e por cores, se o paciente fosse agressivo, se fosse calmo e se queria que ele apenas dormisse, eram esses os motivos dados para os remédios. Além disso, era utilizado tratamento com eletrochoque sem nenhum motivo aparente ou cuidado específico.

Uma evidência muito importante de que o Colônia não tinha mais o objetivo de cura ou cuidado com os transtornos mentais, é a de que inicialmente o hospital fez um convenio 
com um cemitério e, quando esse já não atendia a demanda, construiu um para o próprio uso pelo quantitativo de mortes que ali ocorriam. Naquela época (anos 50, 60 e 70), havia uma crença popular de que suicidas, negros e loucos não podiam ser enterrados juntos com pessoas "comuns" sendo assim, mesmo com o contrato com o cemitério os corpos eram todos entulhados em um buraco qualquer sem no mínimo identificação dos que ali eram enterrados. O documentário mostra ainda que, um dos maiores motivos das mortes era a fome, pois não havia comida no Colônia, no inverno em média 60 pessoas morriam por asfixia, já que não haviam cobertas e nem camas ou colchões (os colchões eram feitos de capim que os internos tinham que colher na área do Colônia) e os pacientes se deitavam um sobre os outros para se aquecerem e, os que estavam por baixo, acabavam mortos.

Outro dado bastante assustador apontado pelo livro de Arbex (2013) é o fato de que muitas faculdades compravam corpos para a dissecação e estudos nas aulas de anatomia. A pesquisa aponta que mais de 1.800 cadáveres foram vendidos para 17 faculdades de medicina de todo o Brasil no período de 1964 a 1980 (inclusive universidades públicas).

Seguindo a descrição dos fatos, vemos que na década de 70 o Hospital Oliveira para Crianças especiais e deficientes foi fechado e por isso algumas crianças que estavam internas lá foram transferidas para o Colônia. Lá as crianças ficavam nuas e conviviam com os adultos, frequentemente as crianças sofriam abusos sexuais dos funcionários e dos outros pacientes e assim ficavam grávidas. Muitos filhos de pacientes eram levados para FEBEM de BH ou eram adotados por funcionários do próprio Colônia.O próprio Documentário relata um casso de adoção de filhos de internos do Colônia.

O documentário apresenta ainda que a história do Colônia só começa a mudar quando passa por uma reforma e uma nova enfermeira e um médico começam a observar essas atrocidades e ambos denunciam utilizando como comparação o campo de concentração. Em 1979 o hospital é visitado por um Psiquiatra Italiano e este declara que nunca tinha visto tal atrocidade em nenhum outro lugar do mundo, em consequência em 1980 as crianças do Colônia são retiradas dali e levados para um lar abrigo dirigido pela Irmã Mercedes e lá eles começaram a ter um resquício de humanidade. O documentário termina apresentando a reforma Psiquiátrica e da saúde mental e o fim do Colônia, o filme também mostra que o Hospital Colônia virou um museu de visitação e um símbolo para o não esquecimento das atrocidades que ali ocorreram. 


\section{Hospital Colônia e a Luta Antimanicomial no Brasil}

Segundo o site Memória da Loucura que é um acervo da história da psiquiatria no Brasil o Hospício Pedro II também chamado de "Palácio dos Loucos" foi o primeiro Hospital Psiquiátrico do Brasil, localizado no estado Rio de Janeiro, fundado em 1852. Até o início do século XIX os "alienados mentais" não recebiam qualquer tipo de tratamento. Se fossem considerados calmos ficavam vagando pelas ruas, já se fossem considerados agressivos ficavam presos e acorrentados em cadeias.

Arbex (2013) ressalta que no ano de 1903 foi fundado na cidade de Barbacena (MG) o Hospital Colônia de Barbacena, este fazia parte de um grupo de mais sete hospitais psiquiátricos, inicialmente este tinha o intuito de ser um Hospital para se tratar Tuberculose e por fim se tornou Hospital Psiquiátrico. No período de 1930 a 1980 o hospital se torna um local de enormes atrocidades, atrocidades essas que eram presenciadas muitas vezes pelos cidadãos de Barbacena e cometidas por quem legalmente tinha o dever de cuidar dos internos. Ocorreu uma superlotação no Colônia fazendo com que o lugar se tornasse, ainda mais em um espaço indigno de vida, tanto que em seus dias de funcionamento ocorreram uma média de 60 mil mortes.

O Colônia se descaracterizou institucionalmente do seu objetivo de cuidar e possivelmente curar os doentes mentais e tornou-se um lugar de barbaridades. Os Hospitais psiquiátricos se caracterizaram como um ambiente onde eram "alocadas" todos as pessoas que eram consideravam erradas para o Estado ou incomodavam alguém. Assim, podemos apontar, através dos dados apresentados pelo livro e documentário que, o objetivo final dessa instituição era muito mais o de uma limpeza social do que tratamentos psiquiátricos. Afinal, no Colônia o "estado clínico" dos internos não era levado em consideração, uma vez que a pesquisa apontou que em média $70 \%$ dos internos eram pessoas sem quaisquer transtornos ou doenças mentais.

A autora nos chama denuncia ainda que, as agressões psicológicas começavam na forma em que os pacientes chegavam ao hospital colônia, os pacientes em sua maioria chegavam por meio do trem que chegava a cidade e iria até o hospital. Esse trem tinha um vagão específico para os tidos como loucos. Isso fez com que esse trem, que chegava duas vezes por semana na cidade, ficasse conhecido como o "trem dos doidos". Segundo relatos os sofrimentos já aconteciam ali no vagão quando os pacientes iam pro Colônia, não recebiam nem água, nem nenhum tipo de alimento, muitos chegavam lá sem ao menos saberem a cidade ou estado que estavam. Os pacientes assim que chegavam eram todos 
desindividualizados, retiradas as suas características, seus cabelos eram raspados, as mulheres e crianças recebiam roupões e muitos homens ficavam nus. Mudavam os nomes exteriores por números ou novos nomes.

Não havia um tratamento específico e adequado para os internos, a equipe de enfermagem desconhecia os medicamentos e os remédios eram separados por cores e destinados de acordo com o paciente, além disso, era ministrado eletrochoque como forma de punição e banhos gelados. Com relação à alimentação, os pacientes não recebiam uma comida adequada, muitos comiam os ratos e outros insetos que estavam por ali no Colônia. A água que bebiam era igualmente imprópria, não potável e muitas vezes tomavam de canos direto do esgoto. Havia uma escravidão feita com os pacientes, onde se era obrigado que eles trabalhassem pela prefeitura e coisas do gênero como justificativa de um tratamento.

O Hospital Colônia de Barbacena foi o epicentro da discussão sobre a necessidade de Reforma Psiquiátrica no Brasil, após mais de 60 mil mortos e vendas de corpos para universidades, houve denúncias de parte dos enfermeiros que expuseram as barbáries do hospital. As práticas ganharam repercussão internacional e isso levou psiquiatras renomados como o italiano Franco Basaglia a comparar os pátios abarrotados do hospital a campos de concentração nazista.

Franco Basaglia foi fonte inspiradora para Reforma Psiquiátrica, quando idealizou e inseriu a prática da desinstitucionalização psiquiátrica. A psiquiatria institucionalizada foi criticada arduamente por diversos autores como Focault (2006) e Goffman (1992). Durante anos de luta por mudanças nas condições de tratamentos dos pacientes com transtorno mental no Brasil, criou-se uma política pública de atenção à saúde mental, conhecida como Lei Paulo Delgado (Lei10.216/01), que definiu a extinção progressiva dos manicômios do país.

Braga (2013) relata que em 1941 foi criado o Serviço Nacional de Doentes Mentais, cuja tarefa era a fiscalização e o financiamento de serviços existentes e articulação de novos, todavia não se realizou nada de significativo. Durante muito tempo o tratamento para as pessoas com transtorno mental eram banhos quentes e frios, cadeiras giratórias, eletrochoques e medicação exagerada.

Com intuito de acabar com os manicômios, o projeto de reforma psiquiátrica no Brasil visava que o paciente fosse encorajado a um exercício maior de cidadania, fortalecendo os seus vínculos familiares e sociais e nunca sendo isolado destes. A partir dessa reforma o Estado não poderia construir e nem contratar serviços de hospitais psiquiátricos.

É necessário deixar evidente que a reforma psiquiátrica teve inicio nos anos 80 , quando também começaram as denuncias das desumanizações ocorridas no Hospital Colônia, 
deve ser observado que até hoje ainda a mesma não foi completa. A luta pela reforma e a garantia de que a nova legislação seja aplicada, ainda é uma questão de discussão.

A Portaria no 224/92 do Ministério da Saúde estabelece diretrizes para o suporte a rede de atenção psicossocial, que tem como princípio tratar o paciente no seu território e zelar pela vida social dele. Não acontecem mais internações em massa e a mesma só acontece no período de crise e é feita nos hospitais gerais ou em CAPS III. Mas o paciente só fíca lá durante a crise, ou seja, no máximo poucos dias e mesmo assim isso é notificado ao ministério púbico para o controle.

\section{Documentário Fantasmas de Ruanda e o Genocídio entre Tutsis e Hutus}

O documentário de 2014 retrata o genocídio de Hutus contra Tutsis ocorrido no ano de 1994 em Ruanda no continente Africano. Os Hutus eram lavradores e eram a maior parte dos cidadãos de Ruanda, já os Tutsis eram pastores e pecuaristas e durante muitos anos foram "patrões" dos Hutus que trabalhavam cuidando dos animais. Os Tutsis representavam entre 10 e $15 \%$ da população de Ruanda. A diferença na forma de trabalho foi o motivo da distinção de classe sociais, os Tutsis eram a elite do país. Para além disso, essas etnias têm uma rivalidade cultural cultivada historicamente e a questão econômica mencionada veio ressaltar os problemas sociais latentes.

Com a independência de Ruanda em 1962 os Hutus tomam o poder administrativo de Ruanda, justificando com a ideia de serem maioria dos cidadãos. O grupo extremista Poder Hutu tomou a liderança e expulsou os Tutsis do país, os Tutsis possuíam um exército rebelde chamado Frente Patriótica de Ruanda (FPR), liderada por Paul Kagame e estavam abrigados em Uganda. A FPR era formada por milhares Tutsis o seu líder futuramente viraria presidente de Ruanda.

Após algum tempo de conflito o presidente de Ruanda o líder dos Hutus aceitou a possibilidade de assinar um tratado de paz entre os Hutus e os Tutsis o mesmo foi assinar o tratado na Tanzânia. Voltando para Ruanda o avião sofre um atentado e é derrubado e os Tutsis acabaram sendo considerados como culpados do atentado. Antes mesmo do fim da noite do atentado, os Hutus começam a matar os Tutsis. A administração militar começa a comandar Ruanda e a partir desse momento muitos passaram a usar o ocorrido como desculpa para justificar a violência que gerou o genocídio.

O governo utilizou-se do monopólio das rádios e de anúncios nas ruas para propagar o ódio e dar autorização e legitimação para matar todos os Tutsis, gerando dessa forma um 
grande horror social que virou um massacre extremamente violento e generalizado. Os assassinatos eram geralmente feitos com facões distribuídos pelas próprias autoridades ou armas domésticas, o documentário aponta que mais de 500 mil pessoas foram massacradas entre 7 de abril e 15 de julho de 1994, algumas fontes dizem até 800 mil pessoas teriam sido mortas fora os incontáveis estupros coletivos.

As tropas da ONU presentes não tinham força suficiente para intervir, mesmo com denúncias dos seus comandantes das atrocidades do que estava acontecendo praticamente nada foi feito. A ONU e a Bélgica tinham soldados na época do massacre, mas receberam ordem de não intervir e se retirarem do país quando dez soldados oficiais belgas foram mortos. Já os EUA não queriam se envolver, os franceses mandaram soldados para tentar criar um ambiente seguro dentro de Ruanda, mas não conseguiram e até hoje são considerados culpados por cumplicidade com o massacre.

O massacre acaba quando mais organizada e disciplinada a FPR avançou e venceu a guerra contra os Hutus, com isso os Hutus fugiram para os países vizinhos e entre os refugiados estavam integrantes do Poder Hutu e as milícias que estavam antes no poder em Ruanda estes não foram julgados mesmo muitos anos depois. A FPR assumiu o poder no fim da guerra promoveu as primeiras eleições diretas para presidente e quem venceu foi Kagame em 2003.

Com o objetivo de julgar os envolvidos no genocídio de Ruanda foi criado o Gacaca que eram os tribunais especiais foram julgados dois milhões de pessoas, negar o genocídio ocorrido se tornou um crime. A diferenciação cultural/étnica Tutsi e Hutu foi banida do país e retirado da identidade, as identidades vinham descritas, Tutsis, Hutu, Batwa ou estrangeiros, já que para os europeus que colonizaram o país os Tutsis e os Hutus eram "RAÇAS" diferentes.

Somente em maio de 2021 de o Presidente da França Emmanuel Macron admite que a França esteve apoiando o grupo genocida de Ruanda e acrescentou que possuíam culpa no massacre. Macron desde 2017 quando entrou na presidência da França busca formas de reatar laços entre os dois países e investigava qual foi o verdadeiro papel da França no ocorrido em Ruanda e no final da investigação constatou-se grandes falhas e imprudências no antigo governo francês. 


\section{Dignidade da Pessoa Humana e a Responsabilidade Civil do Estado $X$ Hospital Colônia}

O Princípio da Dignidade da Pessoa Humana é um Princípio constitucional e é conceito máximo do Estado Democrático de Direito. A Dignidade da Pessoa Humana é um valor moral e espiritual inerente à pessoa, todas as pessoas são dotadas desse direito. Vale aqui ressaltar que esse princípio já existe antes mesmo da própria constituição de 1988. A ideia de dignidade da pessoa humana vem desde o cristianismo e este foi violado pelo Hospital Colônia. O Hospital Colônia de Barbacena era de administração pública. A lei maior em vigor atualmente que é a Constituição da República Federativa do Brasil de 1998 em seu art. $1^{\circ}$, inciso III está explicito Principio da Dignidade da Pessoa Humana.

Art. $1^{\circ}$ A República Federativa do Brasil, formada pela união indissolúvel dos Estados e Municípios e do Distrito Federal, constitui-se em Estado Democrático de Direito e tem como fundamentos:

III - a dignidade da pessoa humana (Brasil,1988)

Como foi citado inicialmente no primeiro tópico durante anos os pacientes do Colônia sofreram as maiores atrocidades e desumanidades possíveis para aquela época, muitos foram torturados e até escravizados, deve ser relembrado aqui que mesmo antes de haver uma jurisprudência que defendesse a teoria da dignidade da pessoa humana, esse já era um ato moral e aqui também cabe citar que a administração do Brasil assina a Declaração Universal dos Direitos Humanos e ambas foram quebradas e ignoradas.

O Estado não cumpriu com o seu dever de Proteção a Dignidade da Pessoa Humana e muito menos com os direitos descritos na Declaração Universal dos Direitos Humanos. Algo que ilustra o que está se querendo demonstrar aqui é o próprio direito à vida que foi ignorado quando morreram mais de 60 mil pessoas. Direitos tidos como básicos não foram de nenhuma forma respeitados, mesmo o Estado tendo ciência dos acontecimentos e total conhecimento de seu dever de assegurar os mesmos e, sendo ele mesmo, o gestor daquela instituição.

Assim, tendo em mente todas as atrocidades ocorridas no Hospital Colônia, ficam duas perguntas enormes a serem respondidas: De quem era a responsabilidade dos atos ocorridos ali no hospital? Por que ninguém foi indenizado ou coisas do gênero?

A Responsabilidade Civil do Estado é a obrigatoriedade legal de indenizar alguém por algum ato praticado por agentes estatais. Vale aqui ressaltar que na própria Constituição Federal no art.37, $\S 6^{\circ}$ cita que a Pessoa Jurídica responsável pelos agentes causadores da omissão ou comissão responderão por eles. 
Art. 37. A administração pública direta e indireta de qualquer dos Poderes da União, dos Estados, do Distrito Federal e dos Municípios obedecerá aos princípios de legalidade, impessoalidade, moralidade, publicidade e eficiência e, também, ao seguinte: (Redação dada pela Emenda Constitucional no ${ }^{\circ}$ 19, de 1998)

$\S 6^{\circ}$ As pessoas jurídicas de direito público e as de direito privado prestadoras de serviços públicos responderão pelos danos que seus agentes, nessa qualidade, causarem a terceiros, assegurado o direito de regresso contra o responsável nos casos de dolo ou culpa.

(Brasil, 1988)

Fundamentalmente a responsabilidade do Estado, possui três correntes, mas a mais importante para esse trabalho é a terceira que é a do Risco Administrativo. Majoritariamente adotada na atualidade, ela encara o dano sofrido pelo particular em consequência do funcionamento, puro e simples, do serviço público. Não se cogita se era bom ou mau, o que importa é a relação de causalidade entre o dano sofrido pelo particular e o ato do preposto ou agente estatal. Desde que se prove o dano, o princípio da igualdade dos ônus e dos encargos exige reparação. Não deve um cidadão sofrer as consequências do dano.

Se o funcionamento do serviço público, independentemente da verificação de sua qualidade, teve como consequência causar prejuízo ao individuo, a forma democrática de distribuir por todos os respectivos efeitos conduz à imposição, a pessoa jurídica, do dever de ressarcir o prejuízo. É necessário e suficiente que se demonstre o nexo causalidade entre o ato e o prejuízo causado.

Legalmente a pessoa só pode ser indenizada se alguém for responsabilizado e o Estado não quer assumir essa culpa. A partir do momento que o Estado assumisse essa culpabilização pela omissão e comissão se torna jurisprudência e assim pessoas com histórias parecidas ao do Colônia podem utilizá-las em suas ações contra o Estado. Este afirma não ter ciência das atitudes que aconteciam nos manicômios e essa é a justificativa utilizada para não se isentar da sua responsabilidade. Mas é possível comprovar o contrário, pois o mesmo por meio de suas autoridades levaram inúmeras pessoas para o Colônia, por causa da limpeza social que se era feita. Crimes de tortura não prescrevem então mesmo que demorem anos, o Estado pode ser indiciado pelos crimes cometidos por seus agentes - a ação do Estado é feita pelo agente estatal que no caso seriam os seus agentes públicos como enfermeiros, médicos e cozinheiros. 


\section{O Silêncio pela Banalização do mal}

Ao pensar nem tudo o que acorreu durante cinquenta anos no Hospital Colônia de Barbacena outras perguntas surgem: por que esse horror durou tanto tempo e porque tantas pessoas foram coniventes? Essas perguntas podem ser respondidas tendo como base o conceito de Banalidade do Mal, descrita pela filosofa alemã Hannah Arendt (1999). Conceitualmente a teoria da Banalidade do Mal retrata como a sociedade passa a não se importar mais com as atrocidades que acontecem em seu meio, normalizando o horror. Pode ser notada como a teoria se adequa ao ocorrido em Barbacena quando vemos a narrativa de Daniela Arbex no livro (2013) e documentário homônimo (2016) Holocausto Brasileiro já tratado acima.

Entre tantas situações horrendas, a autora relata uma em particular de um homem que, quando mais novo, via os corpos dos mortos sendo levado para o cemitério e "brincava" junto com outras crianças com esses corpos. Esse mesmo homem fala que chegou a pular o muro baixo do hospício para brincar com os "loucos" de lá. Outro relato citado é de que a própria prefeitura da cidade de Barbacena colocava os pacientes do Colônia para trabalhar na limpeza da cidade e construções de espaços públicos além disso, que o trem dos "doidos" passava pelo centro da cidade e os próprios munícipes tinham a visão dos loucos chegando ao hospício pelo menos duas vezes na semana já sem se incomodar ou questionar. Os ocorridos citados caracterizam como houve a normalização do mal nessa cidade, onde o horror tornou-se algo comum e corriqueiro aceito por todos através de um acordo tácito perverso.

O silêncio social em Barbacena começa a ser quebrado apenas quando jornalistas conseguem uma licença para fotografar e filmar o ocorrido naquele local. Após isso essa quebra de silêncio ocorre novamente quando novos enfermeiros e médicos começam a denunciar as atrocidades do hospital e os relatos chegam até o psiquiatra italiano Franco Basaglia que comparou o que acontecia no mesmo aos campos de concentração nazistas.

Vale aqui pensar que se a comunidade a própria comunidade tivesse feito algo na época as atrocidades talvez não teriam ido tão longe. Cabe ressaltar também que tanto a cidade de Barbacena quanto as universidades de todo o país que compraram os corpos dos pacientes mortos também foram coniventes com os crimes ocorridos no Colônia.

Com o objetivo de tentar retratar o ocorrido, dar voz aos pacientes que passaram pelo Colônia e de fazer com que as memórias dos mesmos não fossem esquecidas e apagadas com o tempo o Jairo Toledo que foi diretor do Colônia idealizou um museu chamado "Museu da 
Loucura". O museu foi inaugurado em 1996 no antigo Hospital Colônia e tem o objetivo principal de ser um tributo as vozes silenciadas no Colônia.

No caso de Ruanda o maior exemplo de banalização do ocorrido ali é a forma de que o genocídio de quase 800 mil mortes foi silenciado. Durante muito tempo não foi noticiado às atrocidades de Ruanda. Também pode ser considerado um exemplo de banalidade em Ruanda os países que apoiavam os líderes Hutus.

\section{Considerações Finais}

Conclui-se que o manicômio é a tradução completa da possibilidade de exclusão, controle e violência. Os muros tem o objetivo de esconder as violências físicas e simbólicas através de uma roupagem que desculpabiliza a sociedade e descontextualiza os processos socio-históricos da produção e reprodução da loucura. Observando isso pode se ver que nunca foi o objetivo do Colônia assegurar e salvaguardar os pacientes que estavam ali sob sua custódia, mas sim castigar, penalizar, maltratar e torturar os mesmos, atitudes essas que seriam de forma física ou psicológica.

Pode se comprovar que o Estado não cumpriu com o dever a proteção da Dignidade da Pessoa Humana e isso fica explicito nos relatos históricos dos ex-pacientes do Colônia. O Estado deveria sim indenizar os ex-internos ainda vivos e os seus familiares pelas atrocidades que ali ocorreram, mas o Estado não se responsabiliza pela omissão e comissão ocorridas ali, possivelmente com o objetivo de não abrir precedentes para futuras ações jurídicas, mas mesmo que uma ação possa ter sido ajuizada até transitar em julgado demorará anos, pela dificuldade de ajuizar uma ação contra o Estado. Não se é possível achar algum excludente de culpabilidade do Estado para se fazer admissível afastar a obrigação da reparação dos danos feitos ao ex-pacientes.

O que aconteceu no Colônia foram crimes institucionalizados cometidos pelo próprio Estado e foi um genocídio. Os Atos ali cometidos são imprescritíveis (não caducam) por tamanha gravidade dos mesmos, sendo assim todos os familiares do Holocausto Brasileiro devem ser indenizados. A justificativa para o silêncio social é sim a normalização do crime acontecido no Colônia.

Levando em consideração a teoria da Banalidade do Mal e ambos os acontecimentos descritos nos documentários podem ser vistos como a sociedade já não considerava mais aquelas perversidades e a sua importância social. 
No documentário Fantasmas de Ruanda vemos uma referência de um etnocentrismo alimentado desde o início da colonização europeia de Ruanda quando os belgas por motivos próprios alimentavam uma já existente rivalidade entre as duas etnias (Hutus e os Tutsis). Com isso podemos observar que desde o processo de colonização já havia uma banalidade da vida das pessoas evidenciada pelo incentivo à rivalidade cultural pré-existente. Nesse caso, podemos ver como o genocídio e o etnocentrismo estavam de certa forma naturalizados nesse local que quando acontece o atentado com o presidente de Ruanda eles liberaram que todos matassem pessoas Tutsis. O mal em Ruanda se tornou banal.

Quando paramos para observar o que aconteceu no hospital Colônia em Barbacena vemos que o mal havia sido banalizado de tal forma que o próprio hospital fez um contrato com o cemitério da cidade, que ficava ao lado do hospital. A cidade ignorava tudo que acontecia naquele local, pois tinha se tornado normal todo esse horror e tristeza.

Em determinado momento do documentário lembro da fala da Daniela Arbex de que ela havia perguntado de quem era a culpa disso tudo e ninguém sabia falar, pois era algo normal, mas uma determinada pessoa que havia passado por tudo aquilo disse que a culpa dos 60 mil mortos era coletiva e que não dava para falar de direito retirando direitos e responsabilidades.

Não se pode retirar a responsabilidade de todos que moravam naquele local, pois o Hospital Colônia movimentava financeiramente a cidade de Barbacena. Os internos trabalhavam na limpeza de ruas, na construção de casas e até costurando roupas, tudo isso para pessoas da cidade, prefeitura e até médicos e enfermeiros. Só vemos uma responsabilidade e uma política publica quando se há uma reformulação com relação a promoção de saúde mental, e quanto ao que houve podemos dizer que o Estado agiu conjuntamente com o que estava acontecendo na época seguindo políticas públicas que hoje são o oposto: desinstitucionalização dos manicômios.

Conclui-se por fim que, quando a banalidade do mal se torna normal vira uma forma de cultura institucionalizada e que em ambos os casos aconteceram isso. Isso fica evidente no caso de Barbacena quando uma pessoa fala que gostava de ver os corpos dos "doidos mortos" e, em Ruanda, quando os países recebiam os Hutus que massacravam os Tutsis. Além disso a ausência do debate social sobre os ocorridos é um dos motivos de não ser tratado de ambos os assuntos nas escolas e graduações e até mesmo na mídia. Como já foi descrito na primeira parte do artigo as vozes dos pacientes foram silenciadas e ignoradas tanto no município de Barbacena como no estado de Minas Gerais e assim também foram silenciadas, ignoradas e desprezadas as vozes das pessoas de Ruanda. A responsabilidade sobre a barbárie dos 
acontecimentos em Ruanda e Barbacena foi sendo diluída numa rede burocrática e política que gradualmente conseguiu que fosse um assunto de pouca relevância social e histórica. Finalizamos esse artigo parafraseando $\mathrm{H}$. Arendt quando diz que "toda dor pode ser suportada se sobre ela puser ser contada uma história" (1999).

\section{REFERÊNCIAS BIBLIOGRÁFICAS}

ARBEX, Daniela. Holocausto brasileiro. In: ARBEX, DANIELA. Holocausto brasileiro: 50 anos sem punição. [S. l.]: Tribuna de Minas, 21 nov. 2011. Disponível em: $<$ https://tribunademinas.com.br/noticias/cidade/20-11-2011/holocausto-brasileiro-50-anossem-punicao.html>. Acesso em: 29 abr. 2020.

ALBERTINI, Lauriani P. Aulas: Origens do totalitarismo de H. Arendt e Holocausto brasileiro de Daniela Arbex da disciplina de Antropologia, Turma de Pedagogia Primeiro semestre de 2020, ISAT - Instituto Superior Anísio Teixeira.

ALBERTINI, Lauriani P. Slide e Apostila: Universalismo e Relativismo Cultural dos Direitos Humanos: Genocídio e Etnocídio. Material didático da disciplina de Antropologia, Turma de Pedagogia Primeiro semestre de 2020, ISAT - Instituto Superior Anísio Teixeira.

ARENDT, Hannah. Eichmman em Jerusalém: Um relato sobre a banalidade do mal. Tradução: José Rubens Siqueira. São Paulo: Companhia das letras, 1999.

BARANYI, Lucas. O que foi a tragédia do Hospital Colônia de Barbacena? Episódio foi um dos mais grotescos da história brasileira. DEURSEN, Felipe Van (ed.). [S. l.]: Super Interessante, 4 abr. 2018. Disponível em: $<$ https://super.abril.com.br/mundo-estranho/o-quefoi-a-tragedia-do-hospital-colonia-de-barbacena/> . Acesso em: 27 abr. 2020.

BASTOS, Othon. História da psiquiatria em Pernambuco e outras histórias. São Paulo: Lemos; 2002.

BRAGA, André Luiz de Carvalho. O Serviço Nacional de Doenças Mentais no governo JK: a assistência psiquiátrica para o Distrito Federal. 2013. 185 f. Dissertação (Mestrado em História das Ciências e da Saúde) - Fundação Oswaldo Cruz. Casa de Oswaldo Cruz, Rio de Janeiro, RJ, 2013.

CONSTITUIÇÃO DA REPÚBLICA FEDERATIVA DO BRASIL. Brasília, DF: Presidência da República, [2016]. Disponível em:

<http://www.planalto.gov.br/ccivil_03/Constituicao/CConstituiçao>. Acesso em: 20 abr. 2020.

CORREIA, Adriano. Arendt e Kant: banalidade do mal e mal radical. Argumentos: Revista de Filosofia, Fortaleza, ano 5, n. 9, p. 63-78, 2013.

FANTASMAS DE RUANDA / Ghosts Of Rwanda (2004) LEGENDA PT. 2014.1 vídeo (1h54min42s). Publicado pelo canal Victor Mendes (TV2). Disponível em:

$<$ https://www.youtube.com/watch? $=\mathrm{vL} 4 \mathrm{~V} 7 \mathrm{UvZzVg \& t}=7 \mathrm{~s}>$. Acesso em: 14 maio 2020. 
FOUCAULT, Michel. Vigiar e Punir. Petrópolis: Editora Vozes, 1999.

GOFFMAN, E. Manicômios, prisões e conventos. São Paulo: Editora Perspectiva,1974.

HOLOCAUSTO BRASILEIRO - 60 Mil Mortes No Maior Hospício do Brasil. 2019.1 vídeo (1h30min50s). Publicado pelo canal Luc Anderssen. Disponível em:

$<$ https://www.youtube.com/watch?v=b6uoiYDfDEI $>$. Acesso em: 15 maio 2020.

MINISTÉRIO DA SAÚDE (Brasil). Conferência Regional de Reforma dos Serviços de Saúde Mental: 15 anos depois de Caracas. Reforma Psiquiátrica e política de saúde mental no Brasil: Conferência Regional de Reforma dos Serviços de Saúde Mental: 15 anos depois de Caracas. 10 nov. 2005.

NADER, Paulo. Curso de Direito Civil: Parte Geral. 10. ed. rev. atual. e aum. Rio de Janeiro: Editora Forense LTDA, 2016. 632 p. v. 1. ISBN 978-85-309-6355-2.

PEREIRA, Caio Mário da Silva. Instituições de Direito Civil: Introdução ao Direito Civil Teoria Geral de Direito Civil. 29. ed. rev. e atual. Rio de Janeiro: Editora Forense LTDA, 2016. 597 p. v. 1. ISBN 978-85-309-6877-9.

PRESSE, France. Macron vai a Ruanda, reconhece "responsabilidades" da França no genocídio de 1994 e perde perdão. [S. l.], 27 maio 2021. Disponível em:

$<$ https://g1.globo.com/mundo/noticia/2021/05/27/macron-vai-a-ruanda-e-reconheceresponsabilidades-da-franca-no-genocidio-de-1994.ghtml>. Acesso em: 1 jun. 2021.

PORTARIA SAS/MS. Portaria $n^{\circ} n^{\circ} 224 / 92$, de 29 de janeiro de 1992. Diretrizes e normas para os estabelecimentos assistências em saúde mental. [S. l.], 29 jan. 1992. Disponível em: $<$ http://saude.mppr.mp.br/pagina-319.html $>$. Acesso em: 1 jun. 2021

ROLLEMBERG, Márcia. Retratos da História. In: ROLlEMBERG, Márcia. Memória da Loucura. [S. 1.], 2018. Disponível em:

$<$ http://www.ccs.saude.gov.br/memoria\%20da\%20loucura/mostra/creditos.html $>$. Acesso em: 1 jun. 2021.

SALES, Ana Gabriela. Responsabilidade Civil Do Estado Em Face Das Barbáries Praticadas No Hospital Colônia no Século XX. 26/04/2018. Disponível em:

$<$ https://jornalggn.com.br/artigos/responsabilidade-civil-do-estado-em-face-das-barbariespraticadas-no-hospital-colonia-no-seculo-xx-por-wilson-s-s-neto/>. Acesso em: 20 abr. 2020. 